\title{
CLIENTS' SATISFACTION WITH QUALITY OF MATERNITY CARE SERVICES IN SELECTED PRIMARY HEALTH CARE CENTRES IN IJEBU-ODE LOCAL GOVERNMENT AREA OF OGUN STATE
}

\author{
Awosanya Omolade Oyinola ${ }^{1}$, Dr. Joel. O. Aluko², Ogungbesan Joshua Olufemi ${ }^{3}$ \\ and Olu-Abiodun Oluwatosin $\mathrm{O}^{4}$
}

${ }^{1}$ Department of Public Health Nursing, School of Nursing, Babcock University, Ilisan-Remo, Ogun State, Nigeria. E-mail: omoladeawosanya@ gmail.com

${ }^{2}$ Department of Nursing, University of Ilorin, Kwara State, Nigeria. Email: Joelforfavour@gmail.com

${ }^{3}$ Department of Public Health Nursing, School of Nursing, Babcock University, Ilisan-Remo, Ogun State, Nigeria. Email: phemmiton@gmail.com

${ }^{4}$ School of Nursing, Ijebu-ode, Ogun State, Nigeria. Email: tmtosin@yahoo.co.uk

\section{Cite this article:}

Awosanya O.O., Aluko J.O., Ogungbesan J.O., OluAbiodun O.O. (2022), Clients' Satisfaction with Quality of Maternity Care Services in Selected Primary Health Care Centres in Ijebu-Ode Local Government Area of Ogun State. African Journal of Health, Nursing and Midwifery 5(1), 24-36. DOI: 10.52589/AJHNMNBKSEUJW.

\section{Manuscript History \\ Received: 13 Dec 2021 \\ Accepted: 29 Dec 2021 \\ Published: 18 Jan 2022}

Copyright $\odot 2020$ The Author(s) This is an Open Access article distributed under the terms of Creative Commons AttributionNonCommercial-NoDerivatives 4.0 International (CC BY-NC-ND 4.0), which permits anyone to share, use, reproduce and redistribute in any medium, provided the original author and source are credited.
ABSTRACT: Clients' satisfaction is an essential parameter in the assessment of quality of care and healthcare facility performance. Quality is considered good when adequate infrastructure, supplies, and equipment are in place. This study therefore assessed clients' satisfaction with quality of maternity care services in selected Primary Health Care Centres in IjebuOde LGA of Ogun State. A quantitative design adopting a descriptive, cross-sectional approach was utilized in the study. It was carried out among a total of 309 respondents, adopting a total enumeration method. A structured self-administered questionnaire and an adopted observational checklist was used for data collection and data analysis was done using descriptive statistics in the form of tables of frequencies, percentages, median and Standard deviation to analyze the research questions, while the inferential statistics of T-test was used to analyze the hypotheses. The findings of the study on the services of maternity care received by clients revealed that all the examined maternity care services (ANC services, Childbirth/ Delivery service, PNC service, Counselling service (PMTCT of HIV/AIDS), Obstetric emergency care and Laboratory and imaging (ultrasound scan)) are received in the sampled PHC facilities. Result also shows that clients are highly satisfied with the six (6) examined maternity care services rendered in the PHCs, as discussed (ANC services97.5\%, PNC- 88.7\%, DELIVERY- 92.3\%, Counselling (PMTCT of HIV/AIDS) - 80.9\%, Obstetric Emergency Care - $73.4 \%$ and Laboratory/Imaging- $73.8 \%$ ). The findings also revealed that all the facilities were adequately equipped with essential items needed for the management of labour. Italapo has the highest 
number of essential items (91\%), Ita-osu, Iwade-oke and Itantebo PHC facilities has $89 \%$ each in adequacy of essential items, while Oke-oyinbo PHC facility has $66 \%$ in adequacy of essential items for management of labour.. The finding also shows there is no significant association between maternity care services available at each PHC facility and clients' level of satisfaction. Although, the clients who were satisfied with the services received at PHC facilities were more than those who were less satisfied, the influence of availability of services on their level of satisfaction were not statistically significant; $p$-value $>0.05$. The result also shows that the population of women who booked for ANC service is far more than the population of women who returned for child birth in each centre. The mean difference being 74.6. This was found to be statistically significant.

In conclusion, the findings of this study revealed that the six (6) maternity care services examined in this study were received in the 5 sampled PHCs. Also, on the average, larger percentage of the respondents were satisfied with all the six (6) maternity care services rendered in the 5 selected PHC facilities. Although, the population of women who booked for ANC service is far more than the population of women who returned for child birth in each facility. It is therefore recommended that there should be continuous training of healthcare providers, especially the maternity care service providers so as to improve their performance and consequently raise the level of quality of care.

KEYWORDS: Clients' satisfaction, Maternity care services, Primary Health Care Centre, Quality care. 


\section{INTRODUCTION}

\section{Background to the Study}

Clients' satisfaction is an essential parameter in the assessment of quality of care and healthcare facility performance. An evaluation of clients' satisfaction of the quality of maternity care services at the primary Health Care facilities provides feedback to enhance improved service delivery. Satisfaction of clients' with care had also been identified as one of the essential elements of quality care, which can be used to determine the quality of care being rendered in health centres. Quality services are the cornerstone of any health program. Quality is considered good when adequate infrastructure, supplies, and equipment are in place. In addition, critical to the provision of good quality care is the availability of welltrained, skilled, motivated, and supported staff who are performing to established standards and providing services that are accessible, acceptable, and accountable to the clients and communities they serve.

Quality maternity care services tend to promote health, prevent illness/complications, it's cheaper, encourages promotion of safe-motherhood, prevents maternal mortality etc, but, when the quality of maternity care service is compromised in an healthcare facility, there is tendency of increased maternal morbidity/mortality, use of unskilled personnel, as well as non-use or poor usage of the facility. Maternity care services include an extensive scope of health services mothers are given before pregnancy, during pregnancy, at the time of delivery and in the postnatal period. Maternity care services therefore comprise pre-natal care, childbirth and postnatal care.

Generally, women of reproductive age are vulnerable high-risk group of people for maternity target as they are often associated with health-related issues and diseases. The World Health Organization (2013), reported that approximately 830 women die from preventable causes related to pregnancy and childbirth every day, with $99 \%$ of all these maternal deaths occurring in developing countries. A woman's lifetime risk of maternal death, that is, the probability that a 15-year old woman will eventually die from a maternal cause - is 1 in 4,900 in developed countries versus 1 in 180 in developing countries. In Nigeria, lifetime risk of death of pregnant women is 1 in 23 .

A survey of client satisfaction with healthcare services at healthcare facilities is one of the major tools for measuring the quality of the service delivered. The satisfaction of a patient which is an integral part of hospital services has been widely accepted as a measure of the effectiveness of healthcare delivery (Syed, Nazlee \& Shahjahan, 2017). A published review summarized that the following determines satisfaction with care, these include; accessibility, good physical environment, cleanliness, availability of drugs, supplies and human resources, level of care, privacy and confidentiality, promptness, and adequate emotional support (Srivastava, Avan, Rajbangshi\& Bhattacharyya, 2015). Studies have also shown that following the physician's prescriptions, continuing to use a healthcare facility and recommending their use to others, all depend on how satisfied a patient is with their own previous experience. Also, in a study done by Nang, Mitsuaki, Chris, Cho, Atsuko, Sayed, Kazuhiko and Nguyen (2020), the proportion of pregnant women who were satisfied with healthcare services ranged from $18 \%$ to $35 \%$. Provider's service yielded satisfaction ranging between $25 \%$ and 35\%; meanwhile, facilities in the waiting area had the lowest mean score 
(2.78) for satisfaction. Laboratory service and waiting time at the antenatal clinic were major sources of dissatisfaction.

Existing studies of satisfaction have generally investigated patients' evaluation of services received in order to uncover patient demands and preferences for medical projects and hospitals; they also provided information to health institutions about the areas that need improvement. Previous analysis observed that inpatient satisfaction was influenced by multiple factors, including patient factors (demographic characteristics, physical and psychological status, and expectations), health institution factors (health-staff characteristics, staff-patient interactions, health quality, treatment process, finances, medical facilities, and health organization environment and food service), and governmental factors (social environment, health policy, medical insurance and welfare conditions) (Liu \& Wang, 2014).

Conventionally, decisions about health services are made based on the views of health-care professionals because professionals are perceived to be the repository of knowledge and therefore have the right to determine what is best for the client. This viewpoint is counterproductive to the overall national health goal of ensuring quality health care in Nigeria. The need to include clients' on the quality of care is gaining attention because health-care service providers have realized that it is more cost effective to measure the client satisfaction since it is a "non-invasive indicator of quality of care" (Okeke, Bassey, Oduwole\&Adindu, 2019). The knowledge on the degree of client satisfaction serves as a means of identifying areas of improvement in the quality of services offered and also highlighting the need for corrective actions when clients' expectations exceed what an organization can offer or what a particular program is meant to provide. For clients to be more satisfied with treatment, there is need to provide high quality healthcare which is viewed as safe, timely, effective, efficient, equitable, and patient- centered (Palas, Mausumi, Tikadar, Biswas, Mridha\&Ranabir, 2015). This study is therefore necessary to be conducted in order to assess clients' satisfaction with the quality of maternity care services provided in selected Primary Health Care centres in Ijebu-Ode Local Government Area of Ogun State.

\section{THEORETICAL FRAMEWORK}

This is based on Donabedian model for examining health services and evaluating quality of health care. According to the model, quality of care is drawn from three categories: Structure, Process and Outcomes. Structure, which describes the context/settings in which care is delivered (e.g. hospital buildings/facilities, equipment, personnel/staff, and financial processes supporting medical care, etc.).

Process, denotes the transactions between patients and providers throughout the delivery of health care (whether or not good medical practices are followed).

Outcomes, which refers to the effects of healthcare on the health status of patients and populations (improve patient health in terms of promoting recovery, functional restoration, survival and even patient satisfaction) 


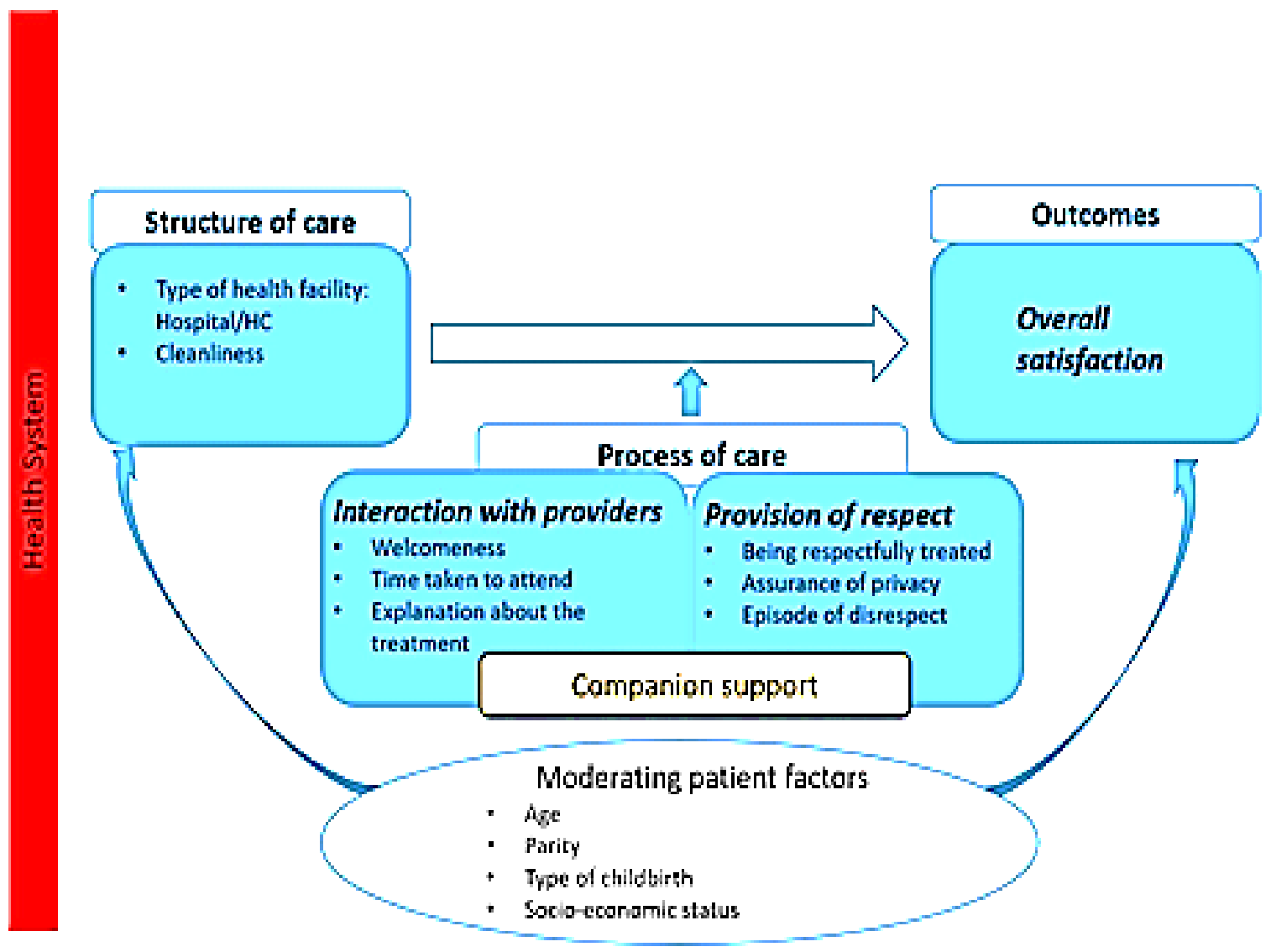

Figure2.1 above represent Conceptual framework of Donabedian model for quality of care

Structure of care

Process of care

Outcome

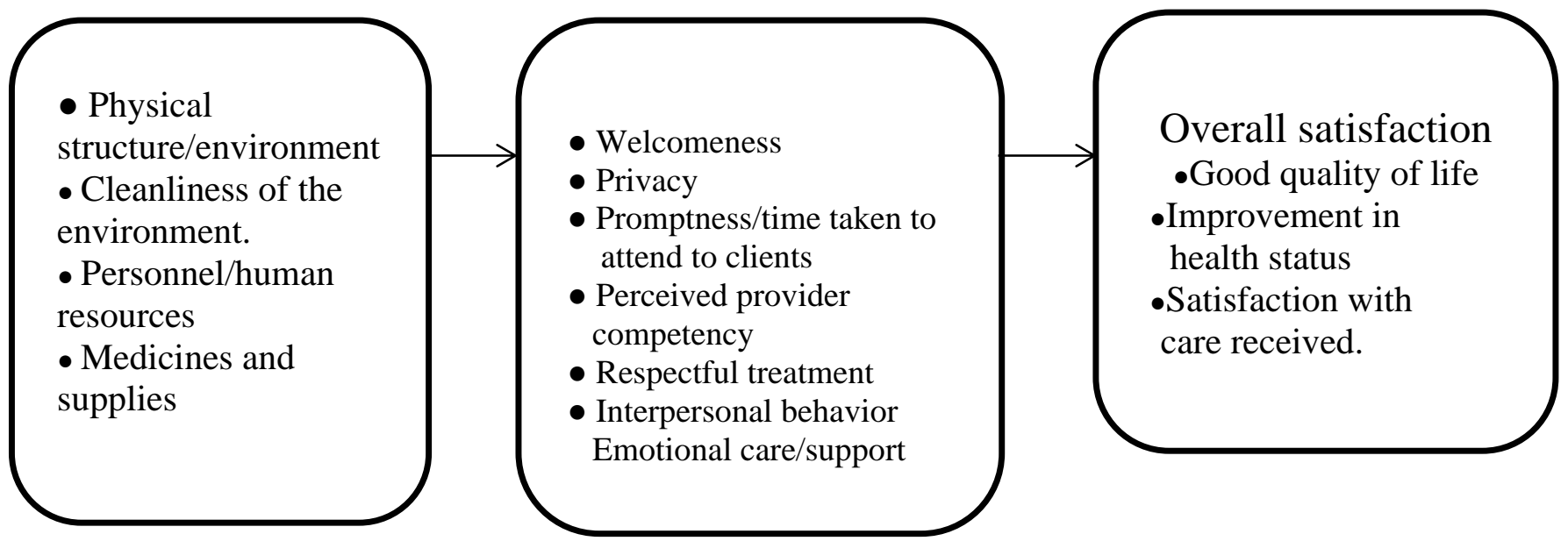

Figure 2.2 above represent Conceptual framework adapted fromDonabedian model for quality of health care 


\section{Application of the Model to the study}

According to the conceptual framework in Figure2.2 above, Donabedian model for quality of health care assumes the existence of three essential factors in assessing quality, these includes the; structure, process and outcome.

Structure is defined as the places where medical care takes place and may include the features of the system, such as good physical environment, cleanliness, and availability of adequate human resources, medicines and supplies.

Process refers to the set of activities that takes place on the one hand, between professionals and, on the other hand, between professionals and patients. It included interpersonal behavior, privacy, promptness, cognitive care, perceived provider competency and emotional support. Outcomes are the consequences for the health and well-being of individuals and society, and include clinical outcomes, quality of life and satisfaction with the care provided.

If the structure is in order or in a good condition/situation, with adequate facilities, equipment and other amenities, the users would be motivated to utilize it and also if the (process) caregivers are welcoming, with good behavior, quick in attending to the clients, respectful in their care, etc., then it would yield a good outcome, which is overall satisfaction with the care and services provided. But, if on the other hand, the structure and the process do not align, the outcome will be dissatisfaction.

According to Donabedian, outcome measures remain the 'ultimate validators' of the effectiveness and quality of healthcare. It is therefore implicit that structure and process have an impact on outcome. Good structure increases the likelihood of good process, which, in turn increase the likelihood of good outcomes.

\section{METHODOLOGY}

\section{Research Design}

The study is a quantitative design, adopting a descriptive, cross-sectional approach to assess clients' satisfaction with the quality of maternity care services in selected Primary Health Care Centres in Ijebu- Ode Local Government Area of Ogun State.

\section{Population}

The target population for the study are women of reproductive age or mothers between 1549years, who had received maternity care services before in the facilities or are currently receiving maternity care services in the selected facilities.

\section{Inclusion Criteria}

The study participants include women of reproductive age who had received maternity care services before in the facility or are currently receiving maternity care services such as ANC service and at least made two or three visits to the PHC centres. Clients who had given consent to participate are also included in the study. 


\section{$\underline{\text { Exclusion Criteria }}$}

Women who had not used the maternity services of the facilities at any point in time or just visiting the facility for the first time for booking. Pregnant women who registered for antenatal care, but have not made up to two or three visits to the facility. Also, women below age $15 y e a r s$ were excluded from the study. Women who do not consent to being a part of the study were also excluded.

\section{Sample size and Sampling Technique}

\section{Sample size determination}

Total enumeration of the clients who attended the facilities for maternity care services was adopted, provided they were eligible and consented to participate in the study. A total of three hundred and nine (309) participants were recruited for the study.

\section{Sampling Technique}

A multi-stage sampling technique was used for the sample selection. This technique involved three stages.

Firstly, five (5) out of the ten political wards was randomly selected.

Secondly, five (5) out of the ten (10) PHC facilities, (though one of the facilities does not provide prenatal care services) was then randomly selected for the study through balloting, without replacement.

Thirdly, it involved total enumeration of clients attending the selected facilities for maternity care services, who consented and are eligible for the study.

\section{Instrumentation}

The study used a self-developed, structured questionnaire of 44-item questions, and an adopted observational checklist of 125 -items (developed by the researcher's supervisor) to elicit information.

The structured questionnaire information was developed according to the stated objectives, research questions and hypotheses of the study. The questionnaire was sectioned into four (4)

Section A: contained questions on socio-demographic data of the respondents, with 9 items

Section B: contained questions on maternity services received at the facility, with 7 items

Section C: contained questions on parameters influencing satisfaction with maternity services (healthcare personnel factors, environment of the facility, and availability of material resources), with a total of 22 items.

Section D: contained questions on level of clients' satisfaction with maternity services received at the PHCs, with 6 items 
The adopted observational checklist comprising of 125-items was also used to assess the facilities and the material resources available for the care of the clients.

\section{Validity/ Reliability of the Instrument}

The face and content validity of the instrument (questionnaire) was established by the researcher. The instrument was given to the researcher's supervisor and other research experts to justify the validity of the content in terms of the clarity, appropriateness of the language and the ability to elicit the accurate information for the attainment of the stated objectives. Necessary modifications were made based on the inputs, before the administration of the instrument.

The reliability of the instrument was ascertained by pre-testing the questionnaire.

\section{Method of Data Analysis}

The collected data at the end of the study were sorted out and coded, descriptive statistics in the form of tables of frequencies, percentages, median and standard deviation were used to analyze the research questions, while the inferential statistics of T-test was adopted to analyze the research hypotheses stated in the study at 0.05 alpha level of significance.

\section{Ethical Consideration}

Ethical clearance was sought and obtained from Babcock University Health Research Ethics Committee (BUHREC) and from the Head of Administrative Services of Ijebu-ode Local Government Area.

\section{RESULTS/ FINDINGS}

Table 4.1: Maternity care services received in the sampled PHC facilities

\begin{tabular}{|l|l|c|c|}
\hline \multicolumn{1}{|c|}{ ITEMS } & No & Yes \\
\hline S/N & \multicolumn{1}{|c|}{} & & \multicolumn{1}{|c|}{ No } \\
\hline 1 & Antenatal Care services & $18(5.8)$ & $291(94.2)$ \\
\hline 2 & Childbirth/ Delivery service & $35(11.3)$ & $274(88.7)$ \\
\hline 3 & Post-natal care services & $96(31.1)$ & $213(68.9)$ \\
\hline 4 & Counselling service (PMTCT of HIV/AIDS) & $123(39.8)$ & $186(60.2)$ \\
\hline 5 & Obstetric emergency care & $92(29.8)$ & $217(70.2)$ \\
\hline 6 & Laboratory and imaging (ultrasound scan) & & \\
\hline
\end{tabular}

*Figures in parentheses indicate percentage 
Table 4.2: Level of clients' satisfaction with the maternity care services.

Scale: 1 - Not Satisfied, 2 - Fairly Satisfied, 3 -Satisfied, 4-Very Satisfied

\begin{tabular}{|l|l|l|l|l|l|l|l|l|}
\hline $\begin{array}{l}\text { S/ } \\
\mathbf{N}\end{array}$ & Item & $\mathbf{1}$ & $\mathbf{2}$ & $\mathbf{3}$ & $\mathbf{4}$ & Median & S.D. & Decision \\
\hline 1 & $\begin{array}{l}\text { Antenatal Care } \\
\text { services }\end{array}$ & $4(1.3)$ & $\begin{array}{l}4 \\
(1.3)\end{array}$ & $\begin{array}{l}108 \\
(35.0)\end{array}$ & $\begin{array}{l}193 \\
(62.5)\end{array}$ & 4.00 & .589 & High extent \\
\hline 2 & $\begin{array}{l}\text { Childbirth/ Delivery } \\
\text { service }\end{array}$ & - & $6(1.9)$ & $\begin{array}{l}96 \\
(31.1)\end{array}$ & $\begin{array}{l}189 \\
(61.2)\end{array}$ & 4.00 & .637 & High extent \\
\hline 3 & $\begin{array}{l}\text { Post-natal care } \\
\text { services }\end{array}$ & $6(1.9)$ & $\begin{array}{l}29 \\
(9.4)\end{array}$ & $\begin{array}{l}117 \\
(37.9)\end{array}$ & $\begin{array}{l}157 \\
(50.8)\end{array}$ & 4.00 & .735 & High extent \\
\hline 4 & $\begin{array}{l}\text { Counselling service } \\
\text { (PMTCT of } \\
\text { HIV/AIDS) }\end{array}$ & $\begin{array}{l}33 \\
(10.7)\end{array}$ & $\begin{array}{l}26 \\
(8.4)\end{array}$ & $\begin{array}{l}99 \\
(32.0)\end{array}$ & $\begin{array}{l}151 \\
(48.9)\end{array}$ & 3.00 & .983 & High extent \\
\hline 5 & $\begin{array}{l}\text { Obstetric emergency } \\
\text { care }\end{array}$ & $\begin{array}{l}31 \\
(10.0)\end{array}$ & $\begin{array}{l}51 \\
(16.5)\end{array}$ & $\begin{array}{l}86 \\
(27.8)\end{array}$ & $\begin{array}{l}141 \\
(45.6)\end{array}$ & 3.00 & 1.01 & High extent \\
\hline 6 & $\begin{array}{l}\text { Laboratory and } \\
\text { imaging (ultrasound } \\
\text { scan) }\end{array}$ & $\begin{array}{l}43 \\
(13.9)\end{array}$ & $\begin{array}{l}38 \\
(12.3)\end{array}$ & $\begin{array}{l}87 \\
(28.2)\end{array}$ & $\begin{array}{l}141 \\
(45.6)\end{array}$ & 3.00 & 1.07 & High extent \\
\hline
\end{tabular}

*Figures in parentheses indicate percentage

Table 4.3: Association between maternity services available at each PHC facility and clients' level of satisfaction

\begin{tabular}{|c|c|c|c|c|c|c|c|c|}
\hline \multirow{3}{*}{$\begin{array}{l}\text { Services } \\
\text { available at the } \\
\text { facility. }\end{array}$} & \multicolumn{4}{|c|}{ Service Received and Level of Satisfaction } & \multirow{3}{*}{$\begin{array}{c}\text { Chi- } \\
\text { Sq. }\end{array}$} & \multirow{3}{*}{ df } & \multirow{3}{*}{$\mathbf{P v}$} & \multirow{3}{*}{ Remark } \\
\hline & \multicolumn{2}{|c|}{ Not Received } & \multicolumn{2}{|c|}{ Received } & & & & \\
\hline & $\begin{array}{c}\text { Less } \\
\text { Satisfied }\end{array}$ & Satisfied & $\begin{array}{c}\text { Less } \\
\text { Satisfied }\end{array}$ & Satisfied & & & & \\
\hline $\begin{array}{l}\text { Post natal care } \\
\text { service }\end{array}$ & $\begin{array}{c}3 \\
30.0 \%\end{array}$ & $\begin{array}{c}32 \\
10.7 \%\end{array}$ & $\begin{array}{c}7 \\
70.0 \%\end{array}$ & $\begin{array}{c}267 \\
89.3 \%\end{array}$ & 3.59 & 1 & 0.1 & NS \\
\hline $\begin{array}{l}\text { Counseling } \\
\text { service }\end{array}$ & $\begin{array}{c}3 \\
30.0 \%\end{array}$ & $\begin{array}{c}93 \\
31.1 \%\end{array}$ & $\begin{array}{c}7 \\
70.0 \%\end{array}$ & $\begin{array}{c}206 \\
68.9 \%\end{array}$ & 0.006 & 1 & 1.0 & NS \\
\hline $\begin{array}{l}\text { Obstetric } \\
\text { emergency care }\end{array}$ & $\begin{array}{c}7 \\
70.0 \%\end{array}$ & $\begin{array}{c}116 \\
38.8 \%\end{array}$ & $\begin{array}{c}3 \\
30.0 \%\end{array}$ & $\begin{array}{c}183 \\
61.2 \%\end{array}$ & 3.92 & 1 & 1.0 & NS \\
\hline $\begin{array}{l}\text { Laboratory and } \\
\text { imaging }\end{array}$ & $\begin{array}{c}3 \\
30.0 \%\end{array}$ & $\begin{array}{c}89 \\
29.8 \% \\
\end{array}$ & $\begin{array}{c}7 \\
70.0 \% \\
\end{array}$ & $\begin{array}{c}210 \\
70.2 \% \\
\end{array}$ & 0.0 & 1 & 1.0 & NS \\
\hline
\end{tabular}


African Journal of Health, Nursing and Midwifery

ISSN: 2689-9418

Volume 5, Issue 1, 2022 (pp. 24-36)

www.abjournals.org

Table 4.4: Difference between women who booked for ANC service and those who returned for child delivery $(\mathbf{N}=5)$

\begin{tabular}{lccccccccc}
\hline $\begin{array}{l}\text { Paired Samples } \\
\text { Statistics }\end{array}$ & N & Mean & $\begin{array}{c}\text { Mean } \\
\text { diff. }\end{array}$ & CI & T & df & sig & R \\
\hline Antenatal booking & 5 & 82.8 & & Lower & Upper & & & & \\
Number of child delivery & 5 & 8.2 & & -31.3 & 180.5 & & & & \\
\hline
\end{tabular}

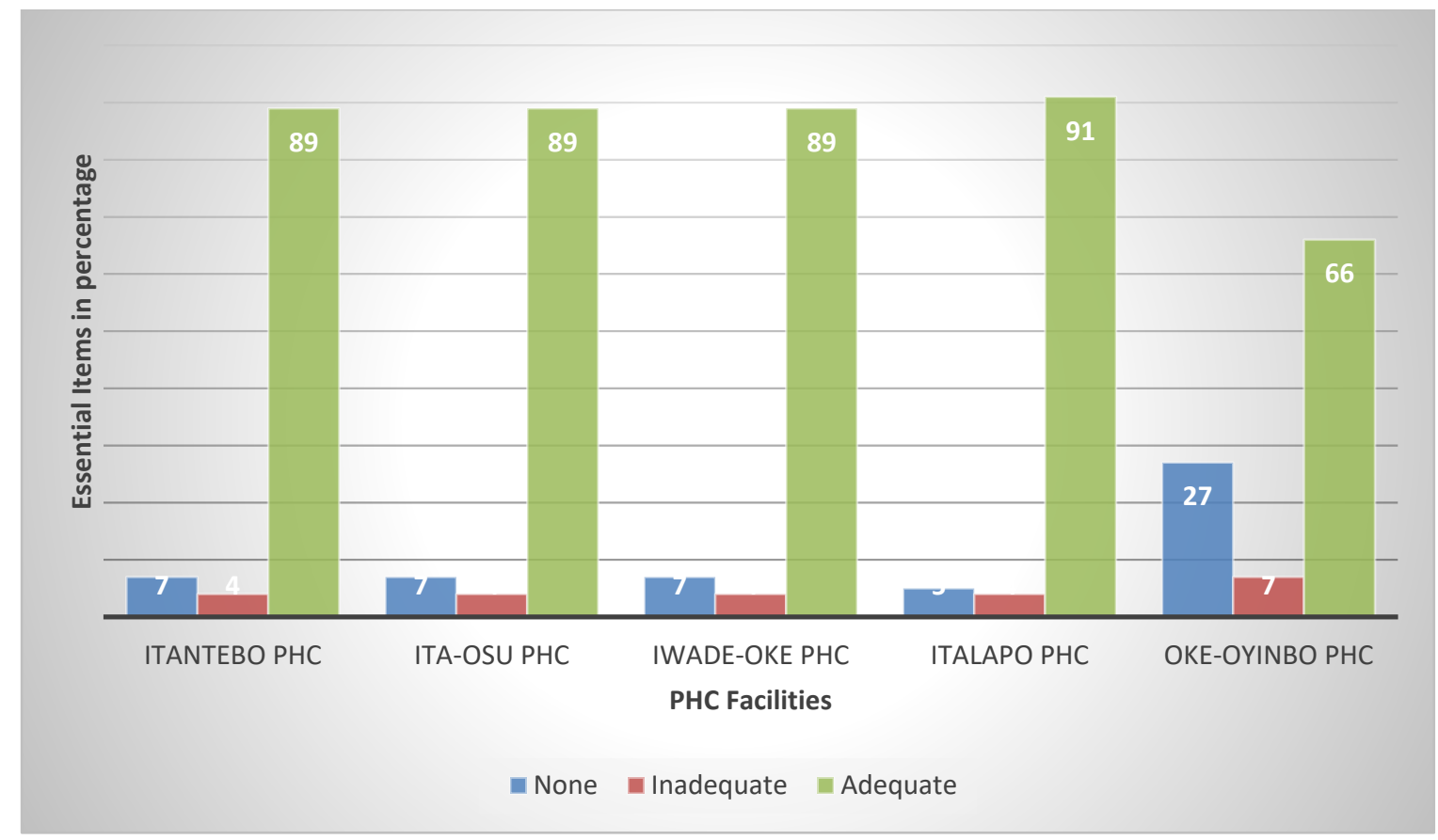

Figure 1: Essential Items for Management of Labour

Figure 4.1 above shows that all the facilities were adequately equipped with essential items needed 


\section{DISCUSSION}

The findings revealed that the six (6) examined maternity care services (Antenatal Care services, Childbirth/ Delivery service, post-natal care service, Counselling service (PMTCT of HIV/AIDS), Obstetric emergency care and Laboratory and imaging (ultrasound scan)) are received in the 5 sampled PHC facilities in Ijebu-Ode Local government area of Ogun State.

Also, the results of the parameters influencing clients' satisfaction (health personnel factors, physical environment and material resources in the primary health care centers in Ijebu-Ode

that clients to a very high extent are satisfied with the parameters, thus influences positively their satisfaction with the quality of maternity care services provided at the PHC facilities.

The results also revealed that clients are highly satisfied with the six (6) examined maternity care services rendered in the 5 sampled PHCs, as shown below: (ANC services- 97.5\%, PNC- 88.7\%, DELIVERY- 92.3\%, Counselling(PMTCT of HIV/AIDS)- 80.9\%, Obstetric Emergency Care $-73.4 \%$ and Laboratory/Imaging- $73.8 \%$ ).

The result also shows that all the facilities were adequately equipped with essential items needed for the management of labour. Italapo has the highest number of essential items (91\%), Ita-osu, Iwade-oke and Itantebo PHC facilities has $89 \%$ each in adequacy of essential items, while Oke-oyinbo PHC facility scored $66 \%$ in adequacy of essential items for management of labour. This will help improve the quality of care rendered to the clients.

The results of hypothesis one (for questionnaire) shows that there is no significant association between maternity care services available at each PHC facility and clients' level of satisfaction. Although, the clients who were satisfied with the services received at PHC facilities were more than those who were less satisfied, the influence of availability of services on their level of satisfaction were not statistically significant; $p$-value $>0.05$. The findings of hypothesis one (for checklist) also shows that the population of women who booked for ANC service is far more than the population of women who returned for child birth in each facility. The mean difference being 74.6. This was found to be statistically significant.

\section{IMPLICATION to Research and Practice}

\section{Nursing Practice}

The study would be useful to primary health care facilities stakeholders and administrators to institute measures to improve the more on the maternity care services given to the clients.

It will also necessitate the need for the healthcare providers (especially the community midwives) to improve the more on the quality of services rendered to the clients, in order to avoid dissatisfaction, and consequently increase patronage of traditional birth attendants (TBAs). 


\section{Nursing Research}

The findings of this study can be used as a baseline and reference in other studies. Hence, there is need to replicate this research in other areas like assessing clients' perception towards other healthcare services in the facilities.

\section{CONCLUSION}

In conclusion, it was deduced that services of maternity care of (ANC services, Childbirth/ Delivery service, PNC service, Counselling service (PMTCT of HIV/AIDS), Obstetric emergency care and Laboratory and imaging (ultrasound scan)) are received in all the sampled PHC facilities and clients are highly satisfied with the six (6) examined maternity care services. This may be due to the fact that the facilities were adequately equipped with essential items needed for service delivery. Although, the population of women who booked for ANC service is far more than the population of women who returned for child birth and post-natal care in the facility.

\section{Future Research}

Research should be carried out in other areas such as; Factors responsible for clients' satisfaction and patronage of traditional birth attendants (TBAs) for maternity care services.

Obstacles that face health care providers in their work place to regularly provide high quality maternity care services.

\section{REFERENCES}

Donabedian, A (2005): Evaluating the Quality of Medical Care, The Milbank Quarterly, 83(4):691-729

Khumalo, N and Rwakaikara, E (2020). 'Patient satisfaction with peri-partum care a BerthaGxowa district hospital, South Africa'. African Journal of Primary Health Care \& Family Medicine. Vol. 12(1)

Liu, W \& Wang, L. (2014). Research of Hospital patient satisfaction and influencing factors on SEM. Soft Sci.; 28(1): 140-144.

Nang, M.,Mitsuaki,M.,Chris, F., Cho,T.,Atsuko, I., Sayed, A., Kazuhiko, M., Nguyen, T. (2020). Satisfaction of Pregnant women with Antenatal Care Services at Women and Children Hospital in South Okkalapa, Myanmar. https://doi.org/:10.2147/266916.

Okeke, H.C, Bassey, P., Oduwole, O.A \&Adindu, A. (2019). Client characteristics and satisfaction with the quality of primary health-care services. Calabar Journal of Health Science; 3(1):1-8.

Palas, D., Mausumi, B., Tikadar, T., Biswas, G.C, Mridha, P., Ranabir, P. (2015). Client Satisfaction on Maternal and Child Health Services in rural Bengal. Indian Journal of Community Medicine 35; 4: 478-481. 
Srivastava, A, Avan, B.I., Rajbangshi, P, Bhattacharyya, S. (2015). Determinants of women's satisfaction with maternal health care: a review of literature from developing countries. BMC pregnancy Childbirth. 15;97

Syed, S.A, Nazlee, S.\&Shahjahan, K. (2017). Patient satisfaction with Health Service in Bangladesh Health Policy and Planning 22(10): 263-273.

World Health Organization(2013).World Health Statistics - A wealth of Information on Global Health. Geneva, Switzerland. 